\title{
Pattern of Childhood Cholelithiasis- Experience in a Tertiary Level Hospital
}

\author{
Khan $\mathrm{SE}^{1}$, Rahman $\mathrm{MM}^{2}$, Parveen $\mathrm{Z}^{3}$, Nessa $\mathrm{M}^{4}$, Hossain $\mathrm{MS}^{5}$
}

DOI: https://doi.org/10.3329/jafmc.v16i1.53839

\begin{abstract}
Introduction: Cholelithiasis is being frequently diagnosed in children, although not as often as in adult. The real aetiology of gallstone formation is poorly understood, but some inciting factors are assumed to be involved in gallstone formation in children. Traditionally cholelithiasis in children is classified as haemolytic or nonhaemolytic in origin. Nonhaemolytic cholelithiasis seems to be more frequent than haemolytic cholelithiasis at present.
\end{abstract}

Aim: To find out the pattern of childhood cholelithiasis presenting in a tertiary level military hospital.

Methods: This retrospective observational study was carried out in the Department of Paediatric Surgery, CMH Dhaka from January 2015 to December 2018. A total of 35 children with cholelithiasis were admitted in this hospital.

Results: During the study period 35 children with cholelithiasis were admitted. Among them maximum children $31(88.6 \%)$ were in the age group of $6-12$ years. Out of them $23(65.7 \%)$ were female and $12(34.3 \%)$ were male making a female to male ratio of 1.92:1. Twelve children (34.3\%) were asymptomatic and 23(65.71\%) were symptomatic. Among symptomatic group $10(28.6 \%)$ had biliary colic, $10(28.6 \%)$ had nonspecific abdominal pain and 3(13.0\%) had acute abdominal pain. Out of these 35 children, only 4(11.4\%) had link with haemolytic anaemia.

Conclusion: Cholelithiasis in children is being recognized with increased frequency in recent years. The ratio of cholecystitis and cholelithiasis varies considerably in different countries and centres. Childhood cholelithiasis has less chance of complication and high rate of resolution.

Key-words: Cholelithiasis, Tertiary level hospital, Children.

\section{Introduction}

Cholelithiasis or gallstones, was found in Egyptian mummies dating back from the eighteenth dynasty $(1550-1292 \mathrm{BC})^{1}$. Gibson first reported gallstone in children in 1737. Gallstone disease in children usually presents as a unique pathological pattern². Gallbladder disease was thought to be an adult entity previously; the incidence is increasing in children in recent past ${ }^{3}$. This is related both to increased detection by widespread use of ultrasonography (USG) and to an increased incidence secondary to dietary changes ${ }^{4}$. There may be an absolute increase in number of cholelithiasis because of prolonged Total Parenteral Nutrition (TPN), ileal resections for necrotizing enterocolitis (NEC), gastroschisis or Crohn's disease. The origin of gallstones in approximately $80 \%$ of children is unknown 5 . The North American Society for Paediatric Gastroenterology, Hepatology and Nutrition (NASPGHAN) reported that almost $2 \%$ of children may have gallstones ${ }^{6}$. Cholelithiasis is commonly classified as being haemolytic or nonhaemolytic in origin ${ }^{7}$. In the past, cholelithiasis in children occurred almost exclusively in children with haemolytic disease like hereditary spherocytosis, sickle cell disease, or thalassaemia. Now most paediatric gallstones are idiopathic ${ }^{8}$. The cause of gallstone formation is deemed to be multifactorial. Stasis of bile, infection, absence of oral feeding and change of the enterohepatic recirculation of bile may be responsible for biliary lithiasis ${ }^{9}$. Before puberty, sex ratio of gallstone in paediatric patients seems to be similar. But afterward, the ratio is altered, more in female in comparison to male as in adult ratio of 4:1 with female preponderance. Gallstones are defined on USG as mobile echogenic material in the gallbladder casting acoustic shadow. While biliary sludge is echogenic bile without acoustic shadows ${ }^{10}$. Obesity is intimately linked with gallstone disease. The influence of obesity is higher in female than male. Gender is mainly associated with pure cholesterol stone ${ }^{11}$. The development of cholelithiasis in children may be affected by age, sex, genetic constituent, race and geographical influence ${ }^{12}$. Cholecystectomy is recommended in paediatric patients with biliary complaints but is not advocated for those with vague complaints. Although the frequency of childhood cholelithiasis is increasing, no study was done in Bangladesh about the pattern of cholelithiasis in children. This study was carried out to find out the pattern of childhood cholelithiasis in a tertiary level military hospital.

\section{Materials and Methods}

This retrospective observational study was carried out on children with cholelithiasis, who were admitted and treated in Paediatric Surgery Department of CMH Dhaka during the period of January 2015 to December 2018, to share our experience with cholelithiasis in children. All children with cholelithiasis irrespective of age, sex, body weight, presentation were included in the study. During this period a total of 35 children with cholelithiasis were admitted and treated in the hospital. They were divided into 2 groups depending on symptoms: asymptomatic and symptomatic. Particulars of all these patients were recorded which included age, sex, height, body weight, clinical feature etc. Data were collected from detailed history, thorough clinical examination and relevant investigations (ultrasonography and $\mathrm{Hb}$ electrophoresis). All children who required surgery underwent operative treatment as elective procedure. They were followed up at 01 month, 03 months and 06 months. All relevant clinical information, investigation results were analyzed.

1. Brig Gen Shams-ud-Din Elias Khan, MBBS, MS, Advisor Specialist in Paediatric Surgery, CMH, Dhaka (E-mail: shams4raiyan@yahoo.com) 2. Maj Gen Md Mahbubur Rahman, MBBS, DPH, MCPS, MMEd, Ex-Commandant, AFMC, Dhaka 3. Lt Col Zinia Parveen, MBBS, MPhil, Associate Professor of Physiology, AFMC, Dhaka 4. Brig Gen Meherun Nessa, MBBS, MS, Advisor Specialist in Paediatric Surgery, CMH, Dhaka 5. Lt Col Md Shakhawat Hossain, MBBS, MS, Classified Specialist in Paediatric Surgery, CMH, Dhaka. 


\section{Results}

During the study period, a total of 35 children with cholelithiasis were admitted in the Department of Paediatric Surgery, $\mathrm{CMH}$ Dhaka. Among them maximum children $31(88.6 \%)$ were in the age group of 6-12 years. Out of them, 23(65.7\%) were female and 12(34.3\%) were male making a female to male ratio of 1.92:1 (Table-I). As per BMI (body mass index) none of the children were obese, 2(5.7\%) were overweight, $8(22.9 \%)$ had normal weight and $25(71.4 \%)$ were underweight (Table-I). Twelve children (34.3\%) were asymptomatic and $23(65.7 \%)$ were symptomatic. Among symptomatic group 10(28.6\%) had biliary colic, 10(28.6\%) had nonspecific abdominal pain and $3(13.0 \%)$ had acute abdominal pain (Table-II). Out of these 35 children, only 4(11.4\%) had link with haemolytic anaemia. $\mathrm{HbE} \beta$ thalassaemia was the commonest haemolytic anaemia found in 2 children (Table-III). Chemical analysis of gallstones was not done in this series.

Table-l: Distribution of children by Age, Sex and BMI $(n=35)$

\begin{tabular}{|c|l|c|c|}
\hline \multicolumn{2}{|c|}{ Characteristics } & Number of children & $\%$ \\
\hline \multirow{3}{*}{ Age } & <1 year & 1 & 2.9 \\
\cline { 2 - 4 } & $1-5$ years & 3 & 8.6 \\
\cline { 2 - 4 } & $6-12$ years & 31 & 88.6 \\
\hline \multirow{2}{*}{ Sex } & Male & 12 & 34.3 \\
\cline { 2 - 4 } & Female & 23 & 65.7 \\
\hline \multirow{3}{*}{ BMI } & Overweig ht & 2 & 5.7 \\
\cline { 2 - 4 } & Normal weight & 8 & 22.9 \\
\cline { 2 - 4 } & Underweight & 25 & 71.4 \\
\hline
\end{tabular}

Table-II: Distribution of children by complaints $(n=35)$

\begin{tabular}{|l|c|c|}
\hline Complaints & $\mathbf{n}$ & $\%$ \\
\hline Asymptomatic & 12 & 34.2 \\
\hline Symptomatic & 23 & 65.7 \\
\hline Biliary colic & 10 & 28.6 \\
\hline Nonspecific abdominal pain & 10 & 28.6 \\
\hline Acute abdominal pain & 3 & 13.0 \\
\hline
\end{tabular}

Table-III: Distribution of children in relation to haemolytic disease $(\mathrm{n}=35)$

\begin{tabular}{|l|c|c|}
\hline Type & Children $(\mathbf{n})$ & $\%$ \\
\hline Non haemolytic & 31 & 88.6 \\
\hline Haemolytic & 4 & 11.4 \\
\hline $\mathrm{HbE} \beta$ thalassaemia & 2 & 5.7 \\
\hline$\beta$ thalassaemia & 1 & 2.9 \\
\hline $\mathrm{Hb}$ E trait & 1 & 2.9 \\
\hline
\end{tabular}

\section{Discussion}

Cholelithiasis is increasingly found in children. It is not only due to increased use of USG but also because of rise in obesity throughout the world and increased haemolytic anaemias in children ${ }^{13}$. The actual number of patients in paediatric group could be under estimated earlier as children with gallstones can report with vague abdominal symptoms ${ }^{3}$. Children with cholelithiasis can report with classical biliary complaints, vague complaints, without any symptom (incidental finding) or complications ${ }^{14}$. Increased USG resulted in enhanced detection of asymptomatic gallstones. There can be true increase of gallstones due to prevalence of recognized aetiologies like TPN, cephalosporin, furosemide use has increasd ${ }^{15}$. Study of gallstone is very important to understand the pathogenesis of gallstones ${ }^{16}$. The epidemiology and aetiological factors of gallstone disease in children vary in different areas. Gallstones are asymptomatic in most of the cases. In asymptomatic cholelithiasis patients the average risk of developing symptom is $2-2.6 \%$ per year ${ }^{17}$. Childhood cholelithiasis is caused by a number of metabolic disorders influenced by both environmental and genetic factors ${ }^{18}$. Predisposing factors of childhood cholelithiasis are separate from those of adults ${ }^{19}$. Predisposing factors include TPN, ileal resection, septicaemia, prolonged diuretic use, dehydration, diabetes mellitus, cystic fibrosis (CF), short bowel syndrome etc ${ }^{20}$. Obesity is an established predisposing factor for gallstone disease in children and increase in childhood cholelithiasis parallels the rise of obesity in children. According to Centre for Disease Control (CDC), Overweight is defined when Body Mass Index (BMI) is at or above the 85th percentile and less than 95th percentile, Normal weight $(<85 \%)$ and Obese $(>95 \%)$. USG study found gallstone in $0.6 \%$ children with normal weight but $2 \%$ of children had gallstones who had BMI above 2 standard deviations ${ }^{21}$. Idiopathic cholelithiasis in children and adolescents is around $20 \%$ to $65 \%{ }^{22}$. It is needed to create awareness among child specialists and general practitioners about the diagnosis and referral of symptomatic gallstone patients for surgical treatment ${ }^{23}$.

The frequency of childhood cholelithiasis is increasing in $\mathrm{CMH}$ Dhaka although no previous published data available to compare as reported in other studies ${ }^{15}$. This increase can be due to increased incidence, increased awareness or increased diagnosis due to availability of USG as diagnostic tool.

Lugo-Vicente described population growth, increased awareness of the entity and frequent use of modern imaging techniques like USG as the cause of increased childhood cholelithiasis ${ }^{24}$. The age of detection of cholelithiasis is related to aetiological factors and median age of detection is between 5 and 10 years $^{25}$. In this study, 31(88.6\%) children were in the age group 6-12 years and only 1 patient (2.9\%) was below the age of 1 year. Literature shows $15.2 \%$ children with gallstone in this age group ${ }^{15}$. This difference could be due to lack of awareness of the condition among treating physicians and USG is not routinely done in these small kids. In this study, out of 35 children with cholelithiasis 23(65.7\%) were female and 12(34.3\%) were male making a female to male ratio of 1.92:1. The sex ratio of gallstone disease before puberty seems to be equal although in adult female to male ratio is 4:13.

Obesity was reported as significant aetiological factor for gallstone in children ${ }^{26}$. But in this study obesity was not a contributing factor, as no child was found obese; only 2 children (5.7\%) were overweight as per BMI. This difference can be due to the fact that obesity is not an epidemic in the country as elsewhere and the age group we included was up to 12 years not 16 or 18 years as included in other studies. There were 12(34.3\%) children in the asymptomatic group in this study. Della corte found 64 patients $(35.3 \%)$ in the asymptomatic group ${ }^{26}$. Others reported $51 \%$ in the asymptomatic group ${ }^{15}$. Out of symptomatic children $23(65.7 \%)$, 
10(28.6\%) had biliary colic, 10(28.6\%) had non-specific abdominal pain and 3(13.0\%) had acute abdominal pain. Other studies reported $43(52.0 \%)$ had biliary colic, 6(7.0\%) acute abdominal pain and 19(24.0\%) nonspecific abdominal pain and 14(17.0\%) were asymptomatic ${ }^{27}$. In this study, haemolytic anaemia was an aetiological factor in 4 children (11.4\%) and 31(88.6\%) had nonhaemolytic cholelithiasis. Studies reported nonhaemolytic cholelithiasis more frequent than haemolytic cholelithiasis recently ${ }^{28}$. Adequate support was not found in laboratory tests in the diagnosis as only half of the children with biliary symptoms showed altered results. This means that laboratory tests may not coincide with the diagnosis of cholelithiasis. Studies revealed similar findings ${ }^{27}$. USG was the main diagnostic tool in this study as shown in other studies. In this study chemical analysis of stone was not done and as such composition of gallstone is not known. The composition of gallstone is unknown in most of the studies and composition was determined depending on visual impression rather than chemical analysis ${ }^{29}$.

\section{Conclusion}

Childhood cholelithiasis is being recognized with increased frequency in recent past. The ratio of cholecystitis and cholelithiasis in children and adult varies considerably in different countries and centres. Childhood cholelithiasis can be either symptomatic or asymptomatic. It is quite difficult to differentiate gallbladder disease from other causes of abdominal pain in children. So cholelithiasis should be excluded in all cases of vague, intermittent abdominal pain in susceptible paediatric age group.

\section{References}

1. Cesarani F, Martina MC, Boano R et al. Multidetector CT study of gallbladder stones in a wrapped Egyptian mummy. Radiographics 2009; 29(4):1191-4.

2. Punia RPS, Garg S, Bisht B et al. Clinico-pathological spectrum of gallbladder disease in children. Acta paediatrica 2010; 99(10):1561-4.

3. Kennedy M. Pediatric Gallstones (Cholelithiasis). Treatment \& Management. 2015. (Online) Available at: www.emedicine.med scape.com /article /927522-treatment.

4. Yamataka A, Kato $Y$, Miyano T. Biliary tract disorders and portal hypertension. In: Holcomb GW, Murphy JP, ed. Ashcraft's Pediatric Surgery, 5th ed. USA: Saunders, 2010:557-77.

5. Lobe TE. Cholecystectomy. In: Puri P, Hollwarth ME. ed. Pediatric Surgery, USA: Springer surgery atlas series, 2006:387-94.

6. North American Society for Pediatric Gastroenterology, Hepatology and Nutrition (NASPGHAN). Digestive Topic: Gallstones - GIKids. 2011. Available at: https://www.gikids.org/ content/116/en/gallstones

7. Juan D, Holcomb III GW. Gallbladder disease. In: Ziegler MM, Azizkhan RG, Allmen DV, Weber TR. ed. Operative Pediatric Surgery, 2nd ed. USA: McGraw-Hill, 2014:789-96.

8. Tecson BB, Tan HL. Cholecystectomy. In: Spitz L, Coran AG. ed. Operative Pediatric Surgery, 7th ed. USA: CRC press, 2013:648-55.
9. Holcomb III GW, Andrews WS. Gall bladder disease and Hepatic infection. In: Coran AG, Adzick NS, Krummel TM, Laberge JM, Shamberger RC, Caldamone AA. ed. Pediatric Surgery, 7th ed. USA: Saunders Company, 2012:1341-55.

10. Murata S, Aomatsu T, Yoden A et al. Fasting and bed rest, even for a relatively short period, are risk factors for ceftriaxone-associated pseudolithiasis. Pediatrics International 2015; 57(5):942-6.

11. Zhu L, Aili A, Zhang $C$ et al. Prevalence of and risk factors for gallstones in Uighur and Han Chinese. World Journal of Gastroenterology 2014; 20(40):14942-9.

12. Karami H, Kianifar HR, Karami S. Cholelithiasis in children: A diagnostic and Therapeutic Approach. J Pediatr Rev 2017; 5(1):e9114.

13. Tannuri ACA, Leal AJG, Velhote MCP et al. Management of gallstone disease in children: $A$ new protocol based on the experience of a single center. Journal of Pediatric Surgery 2012; 47(11):2033-8.

14. Poddar U. Gall stone disease in children, Indian Pediatr 2010; 47(11):945-53.

15. Bogue CO, Murphy AJ, Gerstle JT et al. Risk factors, complications, and outcomes of gallstones in children: A single-center review. Journal of Pediatric Gastroenterology and Nutrition 2010; 50(3):303-8.

16. Cariati A. Gallstone Classification in Western Countries. Indian Journal of Surgery 2015; 77:376-80.

17. Portincasa P, Moschetta A, Petruzzelli M et al. Symptoms and diagnosis of gallbladder stones. Best Pract Res Clin Gastroenterol 2006; 20(6):1017-29.

18. Koivusalo Al, Pakarinen MP, Sittiwet $\mathrm{C}$ et al. Cholesterol, noncholesterol sterols and bile acids in paediatric gallstones. Digestive and Liver Disease 2010; 42(1):61-6.

19. Stawarski A, Iwańczak B, Iwańczak F. Predisposing factors and results of pharmacological treatment using ursodeoxycholic acid of gallbladder stones in children. Pol Merkur Lekarski 2006; 20(116):199-202.

20. Hudson JM, O'Brien M, Beasley SW. Jones' Clinical Paediatric Surgery, 7th ed. UK: Willey Blackwell, 2015:158-64.

21. Garey CL, Laituri CA, Keckler SJ et al. Laparoscopic cholecystectomy in obese and non-obese children. J Surg Res 2010; 163(2):299-302.

22. Kaechele V, Wabitsch $M$, Thiere $D$ et al. Prevalence of gallbladder stone disease in obese children and adolescents: influence of the degree of obesity, sex and pubertal development. Journal of Pediatric Gastroenterology and nutrition 2006; 42(1):66-70.

23. Mehmood A, Khan MA. Biliary stones: An atypical cause of abdominal pain in paediatric age group. Journal of the Pakistan Medical Association 2010; 60(12):1042-4.

24. Lugo-Vicente HL. Trends in management of gallbladder disorders in children. Pediatric Surgery International 1997; 12(5-6):348-52. 
25. Chabchoub I, Bouraoui A, Maalej B et al. Cholelithiasis in children: A single centre experience. Arab Journal of Gastroenterology 2010, 11(4):215-8

26. Corte DC, Falchetti D, Nebbia $G$ et al. Management of cholelithiasis in Italian children: A national multicenter study. World Journal of Gastroenterology 2008; 14(9):1383-8.

27. Wesdorp I, Bosman D, de Graaff A et al. Clinical presentations and predisposing factors of cholelithiasis and sludge in children. Journal of Pediatric Gastroenterology and Nutrition 2000; 31(4):411-7.

28. Walker SK, Maki AC, Cannon RM et al. Etiology and incidence of pediatric gallbladder disease. Surgery 2013; 154(4):927-33.

29. Heubi JE, Suchy FJ, Sokol RJ, Balistreri WF. Diseases of the gallbladder in infancy, childhood and adolescence. Liver Disease in Children 2007:346-66. 